\title{
A Policies of Inclusion and Exclusion for the Persons with Disabilities (PWDs) interlinked with The Climate Change Adaptation: Case Study of Bangladesh
}

\author{
Natasha Israt Kabir \\ Department of Law and Justice, Jahangirnagar University, Dhaka, Bangladesh \\ Email: natashaisratkabir@gmail.com
}

\begin{abstract}
The paper aims to see so far the policies have been recommended and implemented which is interrelated with the lives and livelihoods of the vulnerable communities and, as a result, the well-being and safety of persons, communities and countries as a whole have been affected being persons with disabilities so far both by the non-government organizations and what could be done by the government policy makers. Ten percent of the total population of Bangladesh is known as differently able, often called Persons with Disabilities (PWDs) or disabled people according to the survey of Bangladesh Protibandhi Kallayan Somity (BPKS, 2014). It is worth saying that they are often treated with disregard, and so far they are the vulnerable of the society. Yet their role in homes, places of work and communities is often underplayed. So the paper prepares the studies of policies in terms of how we can integrate and mainstream the excluded differently abled /disabled/PWDs through accessibility in people with disabilities friendly policy making. Disasters, many of which are exacerbated by climate change and are increasing in frequency and intensity, significantly impede progress towards sustainable development. Till now we have achieved both the Hyogo and Sendai Framework based on disaster management do have impressions having the framework to be vocal and to ensure the access of the persons with disabilities in terms disasters, many of which are related with the climate change and adaptation. The paper recommends that the "Children with Disabilities" must be included in a separate policy based framework and the two most important terms based on vulnerabilities and hazards should be more inclusive towards the specialization of the accessibility of the persons with disabilities where both the non-government organizations and government can work together.
\end{abstract}

Keywords: Inclusion and exclusion policies; persons with disabilities; climate change; Bangladesh

\section{Introduction}

Climate change is expected to affect people and the environment due to the increasing number and strength of extreme climatic events it causes, which will lead to a rise in the vulnerability of natural and social systems that is unique to each circumstances of adaptation and their preparedness in terms of disaster. The Intergovernmental Panel on Climate Change (IPCC, 2001) published the assessment of the world's capacity to cope and adapt with the impacts of the climate change, where it stated that the most 
affected people are those who are least able to cope with the risks of livelihood it will bring. Oxfam Annual Report (2010) highlighted that poverty takes a great role in determining the vulnerability of people to respond to climate change because poor people will have limited access to and control over factors such as land, credit, information, mobility, and education that will determine their adaptive capacity and resilience. Since these systems are getting more vulnerable to natural hazards, a response from the community is needed to counter the potential detrimental impact of both natural and Man-made disasters. This concept is known as climate change adaptation (Smit, Klein. and Street, 1999, p.199-213).

Two years after entry into force of the CRPD within a ratifying State, the State must present its first national report, using established reporting guidelines on the baseline situation for PWDs and any advancement in CRPD implementation to the UN Committee on the Rights of Persons with Disabilities. Subsequent reports are due four years after submission of the baseline report. At the same time, DPOs and other civil society organizations may present "alternative" reports, which give a non-governmental perspective on the realities for PWDs. Once Concluding Observations are published by the Committee, DPOs and other civil society organizations can ensure that there is follow-up by government ('Convention on the Rights, p.1-20, 2009).

\section{Literature Review}

One-stop service centers for people with disabilities (Protibandhi Seba O Sahajjay Kendra) are operated by the Jatiyo ProtibondhiUnnayan Foundation (JPUF), under the auspices of the Ministry of Social Welfare (MOSW), to provide physical, occupational, speech and language therapy; hearing and vision tests; and assistive devices and mobility aids free of cost. Sixty eight centres were established and operationalized in all 64 districts of the country from 2009 to 2013, with support from the World Bank. Other rehabilitation services are provided by a multitude of NGOs. These programs tend to focus on specific types of disabilities. They vary in size and quality and depend on external donors, both national and international. Community based rehabilitation (CBR) programs, which combine service delivery with community development and advocacy for equitable treatment of persons with disabilities, are supported primarily by NGOs, but they have limited coverage and financing. Progressive policies have been established.

National Coalition priority areas include:

Ratification of the Convention on the Rights of Persons with Disabilities (CRPD) and/or the Optional Protocol (where not ratified)

Ratification is an important step towards institution of human rights of persons with disabilities at national levels. Disable Persons Organizations (DPOs) and other civil society organizations can play an integral role in advocating for treaty adoption.

Passage of specific national legislation based on Disability Rights Fund (DRF) or (DRAF) will need to review any changes to legislation proposed by the grantee to ensure that it is consistent with the CRPD. This review should take place before any new legislation or legislative amendment proposals advance to government to accord with the CRPD. Some countries try to accord all national legislation prior to ratification; others harmonize laws after adoption. In either case, Disabled Persons' Organizations (DPOs) and other civil society organizations can play an important role in advocating for legislative reform, including through legal advocacy.

The existing literature (both Government and non-government policy brief and action plan) in the name of "Adaptation Approaches for the PWDS interlinked with Climate Change Adaptation" give the view that: 
This vulnerable people have not been included in any negotiations and policy level discussions. The gender based issues related with the people with disabilities have been excluded in terms of policy making.

\section{Methodology}

The study used qualitative methods like content analysis, document analysis, and comparative studies. Qualitative methods, Contextual analysis and Casual Interviews have been followed so far. The methodological path for this will begin with literature review to lay the background as well as to narrow down and reframe the research questions and objectives. The sample NGOs from whom I collected the information are the leading NGOS in terms of climate change based action and especially NGOS on working with the persons with disabilities.

One of them is known as Bangladesh Protibandhi Kallyan Somity (BPKS)/Bangladesh Disable Welfare Council. This NGO has been working in Bangladesh for more than 9 years. Therefore I looked for possibilities to talk with the local and International partners with characteristics of being the sample group and the recipient group in terms of having personal interview along with the experts, i.e. Action Aid, Christian Commission for the Development of Bangladesh (CCDB) and Center for Disability in Development (CDD).

\section{Production of and/or Follow up to Reports Submitted to Other UN Human Rights Monitoring Mechanisms such as the Universal Periodic Review (UPR) of the Human Rights Council or to Other Committees of Experts from Other Human Rights Treaties}

The Universal Periodic Review (UPR) is a UN monitoring process which involves a review, under the auspices of the Human Rights Council, of the human rights records of all 193 UN United Nations Member States once every four years.

Committees of independent experts monitor implementation not only of the CRPD, but also of all core international human rights treaties. Each Committee is created in accordance with the provisions of the treaty it monitors. In addition to the CRPD, there are 7 other Committees mandated to monitor State Parties' compliance with the following treaties:

Covenant on Civil and Political Rights (CCPR), Covenant on Economic, Social and Cultural Rights (CESCR), Convention on the Elimination of All Forms of Racial Discrimination (CERD), Convention on the Elimination of All Forms of Discrimination against Women (CEDAW), Convention against Torture and Other Cruel, Inhuman or Degrading Treatment (CAT), Convention on the Rights of the Child (CRC), Convention on the Protection of the Rights of All Migrant Workers and Members of Their Families (CMV). It is critical that DPOs join other civil society organizations in reporting to all human rights treaty bodies about the situation of persons with disabilities. ('Convention on the Rights of', p.1-20, 2009)

Advocacy to National or International Agencies Responsible for Development Planning to Ensure that National Action Plans and Programs Aiming to Implement the SDGs Are Inclusive of Persons with Disabilities and Use the CRPD as a Guiding Document

In the context of the Sustainable Development Goals (SDGs), to leave no one behind, it is critical that persons with disabilities are considered and counted as a target group and are involved at all levels of 
national action planning, implementation, follow-up and monitoring. The CRPD - often referred to as both a human rights and a social development treaty because of its expected impact in both areas - can be used to advocate for and guide this inclusion.

The existing literature (both Government and non-government policy brief and action plan) in the name of Adaptation Approaches for the PWDS interlinked with Climate Change Adaptation give the view that: This vulnerable people have not been included in any negotiations and policy level discussions. The gender based issues related with the people with disabilities have been excluded in terms of policy making. ('Conventions on The Rights', p.1-20, 2009)

\section{Hyogo Framework for Action: Lessons Learned, Gaps Identified and Future Challenges}

Since the adoption of the Hyogo Framework for Action in 2005, as documented in national and regional progress reports on its implementation as well as in other global reports, progress has been achieved in reducing disaster risk at local, national, regional and global levels by countries and other relevant stakeholders, leading to a decrease in mortality in the case of some hazards. Hazard is defined in the Hyogo Framework for Action as a potentially damaging physical event, phenomenon or human activity that may cause the loss of life or injury, property damage, social and economic disruption or environmental degradation. Hazards can include latent conditions that may represent future threats and can have different origins: Natural (geological, hydro meteorological and biological) or induced by human processes (environmental degradation and technological hazards). Reducing disaster risk is a costeffective investment in preventing future losses Effective disaster risk management contributes to sustainable development. Countries have enhanced their capacities in disaster risk management. International mechanisms for strategic advice, coordination and partnership development for disaster risk reduction, such as the Global Platform for Disaster Risk Reduction and the regional platforms for disaster risk reduction, as well as other relevant international and regional forums for cooperation, have been instrumental in the development of policies and strategies and the advancement of knowledge and mutual learning. ("Sendai Framework for Disaster Risk Reduction (SFDRR)”, 2015-2030, p.3-4)

Overall, the Hyogo Framework for Action has been an important instrument for raising public and institutional awareness, generating political commitment and focusing and catalyzing actions by a wide range of stakeholders at all levels. Evidence indicates that exposure of persons and assets in all countries have increased faster than vulnerability. Vulnerability is defined in the Hyogo Framework for Action as:

The conditions determined by physical, social, economic and environmental factors or processes, which increase the susceptibility of a community to the impact of hazards) has decreased, thus generating new risks and a steady rise in disaster related losses, with a significant economic, social, health, cultural and environmental impact in the short, medium and long term, especially at the local and community level.

Recurring small-scale disasters and slow-onset disasters particularly affect communities, households and small and medium-sized enterprises, constituting a high percentage of all losses. All countries especially developing countries, where the mortality and economic losses from disasters are disproportionately higher are faced with increasing levels of possible hidden costs and challenge in order to meet financial and other obligations. Over the past few decades, the world witnessed significant transformations and shifts in the climate change adaptation based policies as a result of globalization, regionalization and technological advances. The reach of globalization runs deep and wide, leaving indelible impacts on societies in multiple areas and at all levels. The pathways from victimization to adaptation are more twisted and complex. Lifelong practices and security can no longer be taken for 
granted. New forms of policies have emerged, in some cases favoring the policy makers, and in others not allowing persons with disabilities to have greater flexibility to meet their crisis of livelihood.

\section{Sendai Framework for Disaster Risk Reduction (SFDRR) 2015-2030 Closely Views the Inclusion of Persons with Disabilities to Address the Linkages Between Climate Changes at the Local Community Level}

There are evidences which show that the losses and damages of people, property, lives and livelihood in all disaster prone countries have been increased more than previously and rapidly apart from securing our vulnerabilities and reduction of hazards and risks. The procedure of non-risk shows it more clearly about our new potential risks and vulnerable conditions are increasing in an alarming way along with the steady rise of disaster based losses with a significant changes of social, economic, health, cultural and environmental impact in the short, medium and long term, especially at the local community levels The Sendai Framework for disaster risk reduction which is closely related with the climate change adaptation as the first major agreement around post 2015 development agenda, with four priorities, seven targets, and 13 guiding principles for action including a people centered action and recognition of disability inclusion. (Sendai Framework for Disaster Risk Reduction (SFDRR), 2015-2030, p.9-10)

\section{Types of Disabilities: Sampling Through the Pilot Project of Bangladesh Protibandhi Kallyan Somity /Bangladesh Welfare Association for the People with Disabilities (BPKS)}

There are 6 types of disabled people found in the survey. The types are included in the data analysis, as far as uniqueness of needs of reasonable accommodation or assistive devices are concerned. Physical disability is the dominating figure, whereas speech and hearing are less common. 
Table 1 Types of disability

\begin{tabular}{|l|l|l|l|l|l|l|l|l|}
\hline Areas & $\begin{array}{l}\text { Total } \\
\text { popul } \\
\text { ation }\end{array}$ & $\begin{array}{l}\text { Total } \\
\text { PWD }\end{array}$ & $\begin{array}{l}\text { Vis } \\
\text { ual }\end{array}$ & Physical & Hearing & Speech & $\begin{array}{l}\text { Intelle } \\
\text { ctual }\end{array}$ & Multiple \\
\hline Dhaka & 13641 & 155 & 28 & 45 & 4 & 24 & 17 & 37 \\
\hline Jamalpur & 22568 & 513 & 113 & 212 & 60 & 36 & 44 & 48 \\
\hline Norsingdi & 26422 & 416 & 56 & 226 & 21 & 25 & 36 & 52 \\
\hline $\begin{array}{l}\text { Moulvibaz } \\
\text { ar }\end{array}$ & 29100 & 497 & 78 & 212 & 56 & 45 & 68 & 38 \\
\hline Chandpur & 29096 & 372 & 61 & 118 & 31 & 52 & 50 & 60 \\
\hline Noakhali & 31217 & 383 & 72 & 164 & 24 & 49 & 24 & 50 \\
\hline $\begin{array}{l}\text { Chittagon } \\
\text { g }\end{array}$ & 22563 & 362 & 22 & 161 & 18 & 35 & 46 & 80 \\
\hline Kurigram & 17561 & 341 & 60 & 155 & 33 & 39 & 26 & 28 \\
\hline $\begin{array}{l}\text { Nilphamar } \\
\text { i }\end{array}$ & 30533 & 493 & 54 & 213 & 28 & 54 & 44 & 100 \\
\hline Bogra & 28442 & 423 & 54 & 173 & 23 & 73 & 53 & 47 \\
\hline $\begin{array}{l}\text { Chapai.N. } \\
\text { Gonj }\end{array}$ & 26030 & 552 & 103 & 239 & 51 & 39 & 51 & 69 \\
\hline Norail & 8742 & 164 & 42 & 70 & 15 & 9 & 10 & 18 \\
\hline \begin{tabular}{l} 
Total \\
\hline
\end{tabular} & 5591 & 4671 & 743 & 1988 & 364 & 480 & 469 & 627 \\
\hline
\end{tabular}

Source: Bangladesh ProtibandhiKallyanSomity (BPKS) Survey Report 2014

In 2014 report by BPKS has shown disabled people's diversity and income status:Baseline survey on the grassroots has been conducted in 12 Unions of 12 DPOD.

\section{Districtwise PWDs}

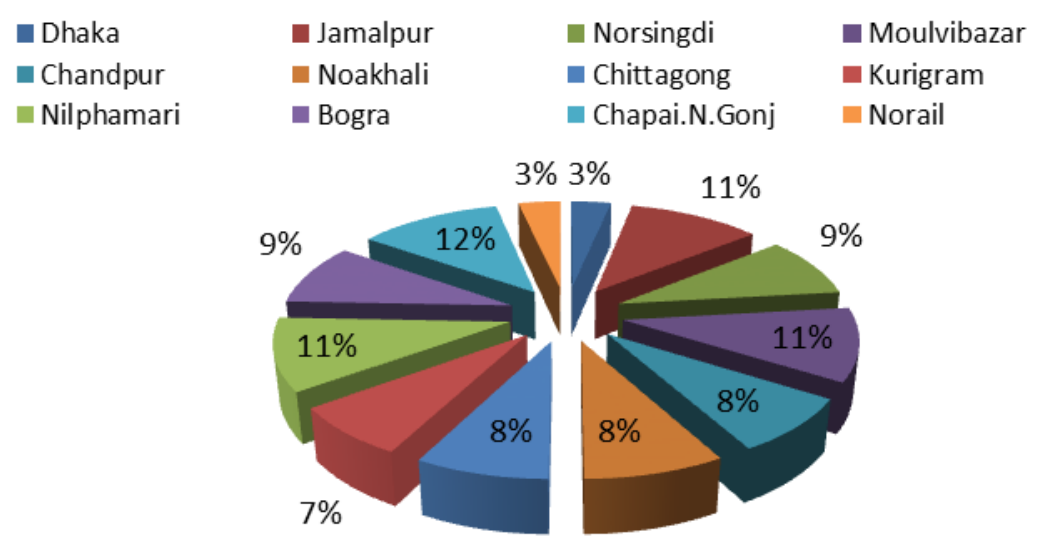


_ sign language-using deaf people have limited access to interpreting in situations involving the police and courts.

_Communication access, and using a different mode of communication, is what makes deaf people different from other people with disabilities. Lack of access to communication often means that deaf people are not included in broader cross-disability coalitions and organizations. This lack of access stymies the participation of deaf people in disability movements.

\section{Dhaka Declaration and Role of National NGO based Movement: Center for Disability in Development (CDD) Has Been Pioneering in This Regards Through the Declaration in Dhaka 2015}

The Dhaka Declaration recalls the United Nations Convention on the Rights of Persons with Disabilities (UNCRPD) principles and articles that call for inherent dignity, equality and inalienable rights of all human beings without any discrimination and exclusion. This declaration was held around December 14-15, 2015 in Dhaka. Climate change disproportionately affects the poor and among the poor the persons with disabilities having the ratio of $20 \%$ and among them $82 \%$ persons with disabilities are living under the below poverty line in the developing countries. ("The Dhaka Declaration", p.1, 2015)

\section{Specific Actions to Be Emphasized Through the Recommendations by the End of 2017:}

Gender Sensitive representations of persons with disabilities must be regarded. Developing inclusive community risk assessment and risk reduction plan framework and guideline for disaster risk management programs and identify the barriers that does limit the access of PWDs in decision making by the end of 2017. Active citizen engagement along with the DPOs, INGOS, NGOS,GOs, UN, Academic Institution, Public and private sectors must be ensured. Set up of an effective management, mechanism and guidelines to compile gender, age and disability ratio based data at pre and pro disaster situation analysis related with climate change to keep hammering the policy makers and disaster management unit. People centered multi hazard early warning system is important. Resilient infrastructure model must be there including schools, house, shelter and hospitals following the principles of universal guideline of design and roll out at all level.

Ensuring support to replicate affordable, accessible and manageable technology, devices and equipment in terms of inclusive humanitarian responses at every level through referring and endorsing the Dhaka declaration at the 'World Humanitarian Summit'2016, regional Disaster Risk Reduction (DRR) 2016 and 2017 and at the first global platform of Sendai Framework 2017.

Representation in the advocacy group of Disaster Risk Management (DRM) to be formed by United Nations International Strategy for Disaster Reduction (UNISIDR), DPOS, NGOs working for the PWDs and DRM jointly working with the national governments to organize a second conference for reviewing the further action which has been taken so far by at least five countries per region and they will declare the focal person to be the representative. ("The Dhaka Declaration", p.3-4, 2015) 


\section{Action Aid's Cluster Village Model:}

\section{Cluster Village for the Landless: A Case of Community Base Comprehensive Approach for Adaptation}

The most vulnerable section of the community living there apprehends the reality to a certain extent and articulated their demands as well towards a comprehensive solution when the project Assistance to Local Communities on Climate Change Adaptation and Disaster Risk Reduction in Bangladesh" started its activities in 2008. The programme started with a detail discussion with the vulnerable communities in a participatory approach. The programme staffs have sat with the community groups, especially poor and excluded women, girls, boys and men to generate the basic analysis of vulnerabilities the community is facing and its link to any climatic changes. It has worked so well that community took the lead in facilitating the analysis process and enhances their understanding on the vulnerability and risks they are facing. Many of the identified risks and vulnerabilities are linked to poverty and unequal access to resources. Later, the following components came out as a programmatic approach to reduce the vulnerabilities and risks to disasters; some of which are directly linked to climatic changes.

Char Kaijuri is the most densely populated village among the four of project covered villages. People from adjacent villages have built their settlement here after losing almost everything including their land and all other productive assets in river erosion. These people are now left with no other alternative but to live in public land, on the slopes of the road or at the edge of mainland. Some also live in other's land not by paying in cash but by serving to their temporary shelter providers on regular basis. Living constantly at the risk of extinction throughout their lives, they have lost the capacity to revive their livelihoods by themselves without any support from outside.

The project at its initial phase was not able to include the landless and marginalized people due to the absence of their land entitlements. The unavailability of khas lands in the locality made it even more problematic. Therefore, the project implemented a cluster of houses on a piece of land for the landless. 'Cluster village', what we call it, is a raised piece of land with houses, latrines and tubewells, a pond, place for homestead gardening and livestock-rearing and a community room for $10 \mathrm{HHs}$. The main purpose of the activity is to include landless people (those who own absolutely no land, not even any homestead land) in a sustainable development process by providing them land entitlement and other supports like house, latrine tube well and livelihood. Based on it the landless will be able to build their livelihood resilience to climate change and variability. Primarily, the project decided to accommodate 16 landless households in this cluster, but after initial plinth-raising, the project decided to lodge 10 households to provide enough space for better protection and promotion of their livelihood through community discussion. The plinth of the cluster is been raised 2 feet above the highest recorded flood level of the area. The design of the cluster has been developed by an expert in collaboration with the GBT. The cluster village includes a pond for fish culture as well as for household needs, a common space with solar system and television for recreation, a demo field of vegetable gardening, and a boat for communication during monsoon. ("Scaling Up Community Based Adaptation', 2011)

\section{Christian Commission for Development in Bangladesh (CCDB) and Climate Technology Development Model}

According to the opinion of the project coordinator Foezullah who is the in charge of the project lighthouse that CCDB started the training on climate change adaptation and mitigation along with the active support of CDD towards a better understanding of the inclusion of PWDs. The 6 months long 
training intends to understand and enhance the ability and knowledge of participants in addressing the challenges of climate change. This particular unit of CCDB is known as Climate Change Unit (CCU). Lighthouse Project has been implementing under Climate Change Adaptation and Mitigation Program of CCDB from January 2012. Goal of project is to create Climate Resilient Communities. Objective of project is to increase adaptive capacity of target population in response to climate change impacts significantly and establish some community based sustainable best practices/models for replication. The project is being implemented in one drought prone district Naogoan and three coastal districts Sathkhira, Bagerhat and Barguna. ("Creating Climate Resilient", 2012).

\section{The Urges to be Forwarded to the Government Ensuring the Role in Terms of Inclusive Policy Making:}

Disabilities are a part of diversity and PWDs do have various requirements. This Diversity and varied requirements must be addressed through the policy making by the government. More than $85 \%$ persons with disabilities recently participated in a global survey from 137 countries entitled with 'Persons Living with Disability and Disaster' conducted by United Nations International Strategy for Disaster relief (UNISIDR), which was conducted in 2013 and published in 2015 stated that they had never been a part of community based disaster management and reduction process. More than half of the survey respondents said they are keen to participate in such process.

Strengthening governance, partnership and collaboration is the most important part along with the key stakeholders to be emphasized based on Dhaka declaration 2015.All the potential stakeholders along with the government do need to set up an effective guideline and mechanism to address the policies in terms of gender, age, class, disabilities, socio-economic and other climate change disaggregated data. Through supporting the community based inclusive data bank would empower and protect the safety net. Removing all kinds of barriers for the persons with disabilities, i.e. social, cultural economical, attitude, physical, communicational and behavioral and support to replicate communication, ICT based tools, devices and equipment and other intermediate technologies to be provided at the local, regional and national level. (“The Dhaka Declaration', p.5,2015)

\section{Short Overview of Climate Based Negotiations at the Paris Conference 2015 to Address the Persons with Disabilities:}

The agenda has become pretty much normal and usual as we guess when after each and every declaration the women, indigenous people and people with disabilities as well as Lesbian, Gay, Bisexual and Transgender ( LGBT ) do fall under the category of being victims. Finally it is about the vulnerable and marginal groups who are going to pay the highest price for the decisions which have been taken so far. At the end again it has become a talk shop when you utterly failed to address the issues being specific as there's no reference to fossil fuels, to historical responsibilities, to polluter pays, to remedies, to binding commitments. (“Kabir", 2015)

\section{Findings and Discussions: Children with Disabilities to be Included}

The above mentioned case studies give us a clear view about our policies to way forward and still now a long way to go. Children especially those with disabilities have not been included in the policy of Ministry of Disaster Management and Relief. However there have been implementations of some positive legislative and policy in terms of inclusion to ensure ramp in the shelter on the basis of 2010 standing 
rule. In terms of social security still now Ministry of Social Welfare do need to go a long way. In this regard joint and collaborative approaches are important along with all the key stake holders.

\section{The active contribution of Persons with Disabilities Along with the Stakeholders to be Ensured at Every Level}

The importance of linking disabilities along with the SDGS depends on the active contribution along with the dynamic collaboration from both the stakeholders and the government which does represent the key perspectives of inclusion.

Sendai Framework to be Implemented from the Period it Started in 2015 and to be Finished within 2030

It is important to reduce the climate change related vulnerabilities along with the extreme causes of socio, economical, health, risk and hazards by 2030 that would ensure both climate change related impacts and poverty as well being a resilient community through adaptation and sustainable solutions for the PWDs.

\section{Ensuring People Centered Approach}

First of all we need to ensure the framework according to the U.N convention along with the Human Rights based approaches to ensure the inclusion at every level of the country. The participation, inclusion and leadership of the PWDs would be able to ensure those treaties and framework along with their meaningful engagement.

\section{Act at Local to National to Global}

There must be a concrete framework, plan and implementation of Sendai framework and follow up process within the timeframe. Dhaka declaration 2015 would be one of the agendas in the upcoming global platform of Sendai Framework.

\section{Conclusion:}

It is the time to encourage all the leaders to highlight the importance of the responsibilities towards the people with disabilities. We need to secure stronger references to the differently able dimensions of climate change in the texts, institutions and mechanisms. It must be informed by the experiences of grassroots level whose are most marginalized and deprived from around the world can and must make a difference. Climate Change adaptation is about justice.

We do need to find out the progresses and actions so far have been implemented for the people with disabilities related to climate change adaptation. We have to discuss on the inclusive and exclusive policies of the government and find out the causes of limitation to implement these efforts. We do require observing the assurances we have that action will be taken to protect the most vulnerable, to the people with disabilities. While doing this study finds that accommodating the deaf and sign language users might be easier along with the mainstream but the wheel chair users, blind, mentally handicapped and others are required to be monitored with special care in terms of climate based adaptation policies, safety and livelihood. 


\section{Acknowledgements:}

I would like to express my gratitude to the initiative which has been initiated by ICCCAD to encourage the enthusiastic researchers entitled with the program "Gobeshona" along with Dr. Saleemul Huq and our honorable trainer and the official from IUCN Dr. Haseeb Irfanullah along with all the officials of ICCCAD and Independent University, Dhaka, Bangladesh.

I would like to show my heartiest gratitude to Bangladesh Protibandhi Kallyan Somity (BPKS) for their cooperation while providing all the required data and report. Last but not least, Action Aid must be added to this list of my acknowledgement. Special thanks go to Ms Julia Taub from ICCCAD, being my mentor for the "Young Researcher Programme"

\section{References:}

Bangladesh Protibandhi Kallyan Somity (BPKS) Annual Consolidated Survey Report. (2014). BPKS. Retrieved from, http://bpksbd.org/publication.php

Creating Climate Resilient Communities Bangladesh. (2012). Christian Commission for Development in Bangladesh (CCDB) .Retrieved from http://ccdbbd.org/whatwedo/ccp/lighthouse

Convention on the Rights of Persons with Disabilities. Geneva. (2009, November18).pp.120.UnitedNations.Retrievedfrom,http://www.ohchr.org/Documents/HRBodies/CRPD/CRPD-C-2$\underline{\text { 3.pdf }}$

Intergovernmental Panel on Climate Change Consolidated Annual Report. (2010).

Kabir, Natasha. (2015, December 14). No hope for women, indigenous people from global South. The Daily Sun. Retrieved from, http://www.daily-sun.com/post/99107/No-hope-for-women-indigenouspeople-from-global-South

Oxfam Consolidated Annual Report. (2010).

Sendai Framework for Disaster Risk Reduction (SFDRR) 2015-2030, (pp.3-4 and 9-10).Retrieved from, http:// www.preventionweb.net/go/sfdrr

Smit, B., Burton, I., Klein, R.J.T. and Street, R (1999, September). The Science of Adaptation: A Framework for Assessment: Mitigation and Adaptation Strategies for Global Change. Netherlands: Kluwer Academic Publishers, 4(4), pp.199-213.

Scaling Up Community Based Adaptation with Local Government in Bangladesh. (2011).Action Aid .Retrieved from,http://www.actionaid.org/bangladesh/where-we-work/scaling-community-basedadaptation-local-government-bangladesh

Situation analysis on Children with Disabilities in Bangladesh. (2014, June). pp. 17-18. United Nations International Children Education Fund (UNICEF). Retrieved from, http://www.unicef.org.bd

The Dhaka Declaration on Disability and Disaster Risk Management. (2015, December 14) .pp.15.Adopted at the at the Dhaka Conference on Disability and Disaster Risk Management Dhaka, Bangladesh.Retrievedfrom, http://www.cdd.org.bd/images/documents/dhaka declaration accessible v ersion.pdf 
http://www.ohchr.org/EN/HRBodies/CRPD/Pages/CRPDIndex.aspx

http://www.ohchr.org/Documents/HRBodies/CRPD/CRPD-C-2-3.pdf

\section{List of Acronyms}

ADD -Action on Disability and Development

APCD- Asia-Pacific Development Center on Disability

BFTW -Bread for the World

BPKS- Bangladesh ProtibandhiKallyanSomity

CSCMP- Civil Service Change Management Programme

CDPF -Commonwealth Disabled Peoples' Forum

CWDs -Children with disabilities

DPI- Disabled Peoples' International

DPO- Disabled People's Organization

DPOD- Disabled People's Organization to Development

EU -European Union GO Government Organization

GDPOD- Grassroots Disabled People's Organization to Development

IAF- International Abilympic Federation

IFHOHYP- International Federation of Hard Of Hearing Young People

JICA- Japan International Cooperation Agency

NADPO- National Alliance of Disabled People's Organization

NGO- Non-government Organization

PSID- Persons with disabilities Self Initiatives to Development

PWDs -Persons With Disabilities

UNCRPD- United Nations Convention on the Rights of Persons with Disabilities

UNDP- United Nations Development Programme

UNESCAP- United Nations Economic and Social Commission for Asia and the Pacific

UNHCR- United Nations High Commissioner for Refugees

WDDF- Women with Disabilities Development Foundation 


\section{WHO -World Health Organization}

WWDs -Women with Disabilities

\section{Copyrights}

Copyright for this article is retained by the author(s), with first publication rights granted to the journal.

This is an open-access article distributed under the terms and conditions of the Creative Commons Attribution license (http://creativecommons.org/licenses/by/4.0/). 